\title{
Correlational study between the indicators of innovation activity and agricultural production in the Russian regions
}

\author{
Aleksey Simonov ${ }^{1}$, Irina Tarasova ${ }^{2, *}$, Nadezhda Vinogradova ${ }^{3}$, Alexandr Stepanov ${ }^{1}$ and \\ Olga Fomenko ${ }^{4}$ \\ ${ }^{1}$ Department of information systems in Economics, Volgograd State Technical University, 400005, \\ Volgograd, Russia \\ ${ }^{2}$ Department of applied mathematics, Volgograd State Technical University, 400005, Volgograd, \\ Russia \\ ${ }^{3}$ Department of philosophy and law, Volgograd State Technical University, 400005, Volgograd, \\ Russia \\ ${ }^{4}$ Department of foreign languages, Volgograd State Technical University, 400005, Volgograd, Russia
}

\begin{abstract}
This article is devoted to the issue of the correlation between the innovation activity and the volume of agricultural production in the Russian Federation in the context of the established documents, defining the security policy in our country. The hypothesis of the correlation between innovation activity and agricultural production in the conditions of the fourth technological revolution is substantiated. The mathematical tools that can be applied in these areas, taking into account the significant differentiation of the Russian regions, have been studied. To obtain the system assessment of innovation activity in the Russian Federation, the developed integrated index of innovation activity in the region has been used. During the study of the correlation between innovation activity and the volumes of agricultural production, the results of correlationalregression model had been specified on the basis of the correspondence analysis method. During the analysis software tools, created in Volgograd State Technical University, as well as statistical packages and also spreadsheet MS Excel, were used. This fact allows to computerize a considerable part of calculations. It was concluded, that the regions with the developed innovative activity are characterized by large volumes of agricultural production, and the volumes of agricultural production can.
\end{abstract}

\section{Introduction}

Ensuring effective innovative development of economy of the Russian Federation is of huge importance for sustainable strategic development of our country. As it is noted in the Strategy of national security of the Russian Federation [1, item 56], "strategic objectives of ensuring national security are development of national economy, and creation of conditions for transition of economy on the new level of technology development". The weak

${ }^{*}$ Corresponding author: tarasova.irina.aleks@gmail.com 
innovation activity, lag in the field of development and introduction of new technologies are the challenges facing the economy of Russia, as it is reflected in [1, item 57] and [2, item 12]. These threats closely correlate with inequality of development of regions: a different level of the innovative development is not only an indicator of inequality of development of regions itself, but also the base for strengthening the differentiation of economic indicators of the regions in future. At the same time, the inequality of development of regions is also reflected as a threat in $[1,2]$.

In our opinion, one of the ways of eliminating a threat of the increasing lag in the innovative development and the growth of the differentiation of the RF regions is the intensification of use of the most perspective technologies in agriculture. Really, though in the majority of modern concepts of the innovative development not enough attention is paid to agriculture, but it is a natural recipient of innovations. If to consider NBIC convergence [3], then modern biotechnologies and information technologies have obvious applicability in agriculture. Such elements of the concept of the fourth industrial revolution [4] as biotechnologies, "green" energy and conservation of energy, 3D - print, have the huge potential for application in agriculture.

The instruments of studying of correlation between a condition of the innovation activity in regions and development of agriculture are considered in this work, also the ways of creating the integrated indicators, carrying out the correlation and regression analysis, the correspondence analysis are considered. The conclusions which, in our opinion, can be applied in management of the regions and the country in general have been made.

\section{Materials and methods}

The contingency of the innovation activity in general and agriculture is, in our opinion, an important task for our country. However the subject of the analysis is extremely difficult therefore the developed tools including modern mathematical models and methods and also the software are necessary to be carried out. That is why we offered a number of the mathematical models and software solutions allowing to estimate extent of the relation between these areas in the regions of Russia in general and in the Volgograd region in particular to estimate the current condition and monitor the dynamics of changes which are going to occur.

As an indicator of the system assessment of the innovative development extent of the region we used the integrated indicator of the innovation activity developed and counted by the staff of the chair "Information Systems in Economy" of Volgograd State Technical University in the RF regions. The focus of this research was directed to the scope of different types of the innovation activity therefore not several private indicators of the innovation activity (such as internal costs on research and development or a number of the HIGHER EDUCATION INSTITUTIONS entering a top 100) which are extremely numerous are used and, often, closely correlate among themselves [5], namely integrated assessment. It should be noted that in Russia there is a number of the known integrated estimates on the basis of which the ratings of the economic development of the regions are constructed [6]. However the application of these estimates at further mathematical modeling has no sufficient justification as their distribution is not complied with the normal law. The index constructed by us is complied with the normal law on a rather high level of importance.

During the creation of the integrated indicator of the innovation activity 25 indicators characterizing various parties of the innovation activity were used (sources: website of the 33Federal State Statistics Service; expert.pa; website of the Ministry of Education and Science). The rated values on each region were exposed to the preliminary analysis, in 
particular, were taken the logarithm for the indicators subordinated to the logarithmically normal law; were led to an interval $[0 ; 1]$. After that the mean values of the received indicators were calculated. The sub-indexes characterizing the availability of the innovation potential in regions, the innovation activity of the region and the extent of the development of the innovation sphere were also calculated. The software product in the Lazarus environment allowing to automate formatting of the entered data, their primary statistical processing and construction of the index was created for the calculations automation. The integrated indicator of the innovation activity of the Russian regions for last five years was constructed by means of this software product. The more detailed process of constructing this integrated indicator and also some conclusions received at its studying are reflected in [7].

For the characteristic of the level of development of agriculture in the region we used the data about the agriculture products cost in 2018. The cities of Moscow, St. Petersburg and Sevastopol as qualitatively different units were excluded from the list of the regions. The remained data did not submit to the normal law (P-value of the calculated criteria, in particular, by Kolmogorov-Smirnov and Shapiro-Wilk's criterion, lower than 0.01, that it is possible to reject the hypothesis of normality of these data with probability more than $99 \%$ ). In this regard, the data were found the logarithm that allowed to increase P-value to the level of $50 \%$ at which the hypothesis of normality cannot be rejected.

The logic of the method of the correspondence analysis is close to the logic of the main component method, and consists in studying the statistics $\chi 2$, connected with the contingency table. This statistics is approximated by orthogonal components (factors) that allow to reduce the dimension of data to necessary level. As a rule, the final version is the information representation about the qualitative values standing in lines and columns on the surface (two measurements), or in space (three dimensions). At the same time the points lines (and points columns) which are at small distance by the results of the analysis will be close to each other on relative frequencies (and will have close economic characteristics). On the contrary, the points which are at considerable distance will differ greatly from each other.

The main advantages of this method is the possibility of simple interpretation of the results which are, as a rule, displayed graphically after the separation of two (or three) orthogonal components; and also high flexibility concerning a type of the basic data. Customization codes were used for the automation of calculations Excel MS.

The considered tools were applied by us to carry out the correlation analysis between the condition of the innovation activity and agriculture in the regions of the Russian Federation. The results of such analysis are described below.

\section{Results}

At the first stage of the correlation analysis between the condition of the innovation activity and agriculture in the regions of the Russian Federation the methods of the correlation and regression analysis were used. The correlation and regression analysis showed the availability of direct moderate connection $(\mathrm{r}=0.51$, significant on the level of significance $>$ $99 \%$, see fig. 1). 


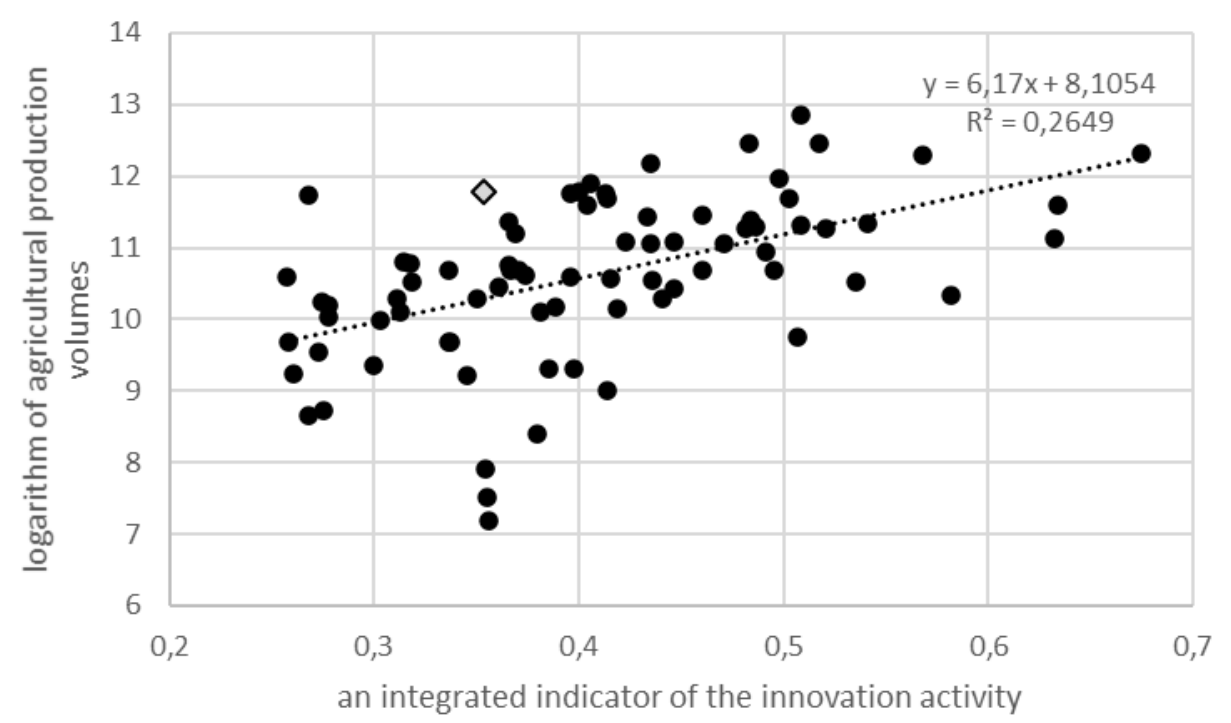

Fig. 1. Correlation model between the innovation activity and the volume of agricultural production.

Thus, our initial hypothesis of the correlation availability between the indicators of the innovation activity and the level of development of agriculture was confirmed. The moderate narrowness of correlation $(\mathrm{r}=0.51)$ allows to make general conclusions about the direction of correlation, however the constructed model does not provide the accuracy necessary at forecasting and planning at the level of certain regions. Much more interesting results were received when using pivot table 1 and also during application of the correspondence analysis method.

As we see from table 1, high volumes of agriculture are specific for the regions with high rates of innovation activity that confirms the hypothesis that agriculture is the major recipient of the created innovations. On the other hand, very high dispersion of volumes of farm-production - from the biggest to the smallest ones is specific for the regions with low innovative development.

Table 1. Correlation between the innovation activity and volumes of agricultural production.

\begin{tabular}{|c|c|c|c|c|c|c|}
\hline \multirow{2}{*}{$\begin{array}{l}\text { Indicator of the } \\
\text { innovation } \\
\text { activity }\end{array}$} & \multicolumn{5}{|c|}{ Volumes of agricultural production } & \multirow{2}{*}{$\begin{array}{c}\text { Grand } \\
\text { total }\end{array}$} \\
\hline & low & $\begin{array}{l}\text { below an } \\
\text { average }\end{array}$ & average & $\begin{array}{l}\text { above an } \\
\text { average }\end{array}$ & very high & \\
\hline Low & 0 & 4 & 12 & 3 & 1 & 20 \\
\hline below an average & 3 & 5 & 6 & 10 & 5 & 29 \\
\hline average & 0 & 0 & 4 & 13 & 4 & 21 \\
\hline above an average & 0 & 0 & 2 & 2 & 2 & 6 \\
\hline very high & 0 & 0 & 0 & 2 & 1 & 3 \\
\hline Grand total & 3 & 9 & 24 & 30 & 13 & 79 \\
\hline
\end{tabular}




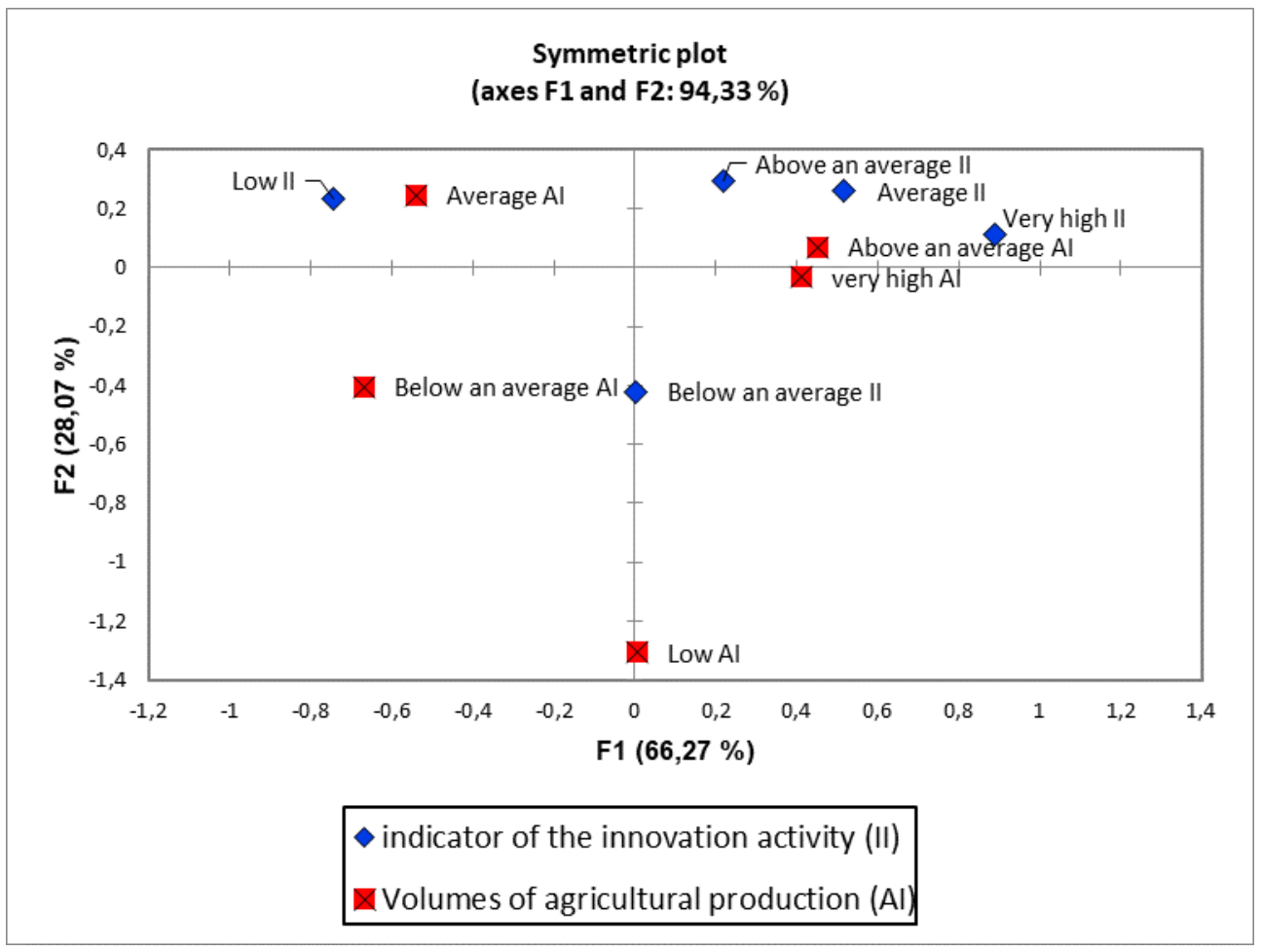

Fig. 2. Analysis results of compliance of indicators of the innovation activity to the volumes of agricultural production.

Let's analyze the results received by the means of a correspondence analysis method (see fig. 2). It should be noted that the reduction of dimension to two allowed us to explain nearly $95 \%$ of inertia (values $\chi 2$ ), the use of three-dimensional charts would allow to raise this indicator up to $99.5 \%$. From the figure it is vivid that the high levels of agricultural production are specific for the regions of Russia with a high and average level of development of the innovation activity. It can be explained both with the direct impact of one on another one, and the availability of general factors (for example, concentration of the population which leads to strengthening the innovations and increasing the harvesting). Average volumes of agricultural production are specific for the regions with low innovation potential. And here for the regions with low volumes of agricultural production and very low innovation potential the relation between these indicators is not specific.

\section{Discussion}

In the conducted research the results of application of the correlation and regression analysis and a method of the correspondence analysis for the solution of a modeling problem of the correlation between the indicators of the innovation activity and a condition of the agricultural industry in the regions of the Russian Federation are shown. The research showed that the application of a method of the correspondence analysis allows to increase the quality of the analysis considerably, to reveal the features of behavior of separate groups of objects. As a development of the research direction, it is possible to consider the possibility to use the methods of clustering and different variations of the main component method. 
From the economic point of view, the received results can be interpreted differently. On the one hand, it is possible to assume that the regions with low innovation activity are considerably non-uniform and to look for the reasons of such heterogeneity in the features of business activities in these regions, confirming the results with the methods of classification and clustering. On the other hand, it is possible to assume that all advanced regions conduct uniform economic policy sufficiently, and each of lagging behind "is unhappy in its own way". In this case, the state is faced with a problem to change the model of economic policy of the lagging behind regions if the problem of high differentiation of the regions is really considered as a threat for the economy of our country.

\section{Conclusions}

The mathematical methods and software solutions applied by us have allowed us to look more deeply at the studied problem, to reveal the regularities which can be applied at the acceptance of management decisions on the level of the regions and the state in general.

\section{References}

1. The national security strategy of the Russian Federation, approved by decree of the President of the Russian Federation No. 683 31.12. 2015.

2. The economic security strategy of the Russian Federation for the period until 2030, approved by decree of the President of the Russian Federation No. 208, 05/13/2017.

3. J. Schummer, From Nano-Convergence to NBIC-Convergence: "The Best Way to Predict the Future is to Create it" (2009).

4. K. Schwab, The Fourth Industrial Revolution: what it means, how to respond (2016)

5. 5. A. B. Simonov, Yu. G. Onoprienko, D. F. Miller, Modeling of the features of the distribution of innovative activity in Russian regions, Economic security of Russia and the development strategies of its regions in modern conditions (2015)

6. 6. Statistical collections of the HSE. Rating of innovative development of constituent entities of the Russian Federation, 4 (2016) URL: https://www.hse.ru/primarydata/rir2016

7. 7. I.A. Tarasova, A. B. Simonov, I. E. Simonova, K.A. Kalnaya, Building a systematic assessment of the innovative development of Russian regions, Management of the development of large-scale systems (2017) 